\title{
Research on Training Mode of Innovative Talents in Electrical Specialty
}

\author{
Du Yanhong \\ College of Engineering and Technology \\ Tianjin Agricultural University \\ Tianjin, China \\ yanhong_du@163.com \\ Li Jin \\ College of Engineering and Technology \\ Tianjin Agricultural University \\ Tianjin, China \\ 503581900@qq.com
}

\author{
Wu Haiyun \\ College of Engineering and Technology \\ Tianjin Agricultural University \\ Tianjin, China \\ 283699240@qq.com \\ Wang Jinwei \\ Sinoma Energy Conservation Ltd \\ Tianjin, China \\ 834725819@qq.com
}

\begin{abstract}
In line with the principle of "solid basis, wide caliber, strong practice and stressed innovation", focusing on innovation in knowledge, spirit, personality and ability, the training mode of innovative talents in electrical specialty and its achieving methods have been presented. By means of constructing the reasonable, complete, high-efficient and innovative curriculum system, optimizing the teaching staff of innovative entrepreneurial education, setting up the multilevel practical training platform for the students, establishing the comprehensive subject competition system, creating diversified entrepreneurial activity, cultivating technological entrepreneurial team and perfecting the overall dual stepped management and guarantee mechanism, to realize the improvement of social responsibility, innovative spirit, entrepreneurial consciousness and entrepreneurial ability of the students in electrical specialty, for meeting the new opportunity and prospect, and adapting to higher requirements and challenges.
\end{abstract}

Keywords-Electrical Specialty, Innovative Talents, Training Mode, Achieving Methods

\section{INTRODUCTION}

The innovative entrepreneurial education, as the double hot topics in the theory and practice of our national higher education in recent years, is derived from America and then spread to many countries. Nowadays, the innovative talents training abroad has realized the initiation, assessment and incubation of project, and finally moved towards the market, and has obtained immense economic benefit, meantime, it also has provided more jobs and obtained more and more acceptance through science and technology to promote the social development. In order to better carry out the innovative entrepreneurial education and talents training, in May 2010, Ministry of Education had issued Opinion on Devoting Great Efforts to Promoting the Innovative Entrepreneurial Education in Institution of Higher Education as well as Self-employed Entrepreneur Work of the Graduates, in March 2012, in Several Opinions on Comprehensively Improving the Quality

Innovation and Entrepreneurship Training Reform Model Projects of Tianjin Agricultural University (20170812) of Higher Education, Ministry of Education had again expressly put forward that strengthening innovative entrepreneurial education and working instruction service and putting the innovative talents training to the whole process. In May 2015, The General Office of the State Council had issued Implementation Opinion on Deepening the Innovative Entrepreneurial Education Reformation in Institution of Higher Education, the reformation on innovative talents training and on the curriculum system has been comprehensively launched. [1-3]

In order to better implement the national talents training policy, meet new opportunity and prospect, adapt to higher requirements and challenges, the paper carried out the research in combination with the current education practice of electrical engineering and the automation specialty, to explore the training mode of innovative talents, so as to achieve the training target of improving the collaborative innovation capability, entrepreneurial consciousness and entrepreneurial ability of the students.

\section{BUILD UP THE INNOVATIVE TALENTS TRAINING CONCEPT}

At present, China's higher education is mainly composed of professional education. The implementation of professional education is based on the training program of professional talents. The professional training programs are mainly supported by different curriculum systems. Therefore, in order to practically and effectively integrate innovative entrepreneurial education into the whole process of talents training, it is not simply to increase the number of innovative entrepreneurial courses in the training program, but to integrate the concept of innovative entrepreneurial education into all aspects and various curriculum systems of the existing talents training programs [4], to transform the educational thoughts, freshen up the educational concept, deepen the reformation of talents training mode and education and teaching on the basis of professional education, which shall 
not only cultivate students' professional knowledge and skills, but also enhance students' social responsibility, innovative spirit, entrepreneurial consciousness and entrepreneurial ability as the core, replacing the goal of "focusing on cultivating independent innovative entrepreneurs for a small number of students" with "focus on cultivating job innovative entrepreneurs for all students", so as to continuously improve the quality of talents training.

\section{ESTABLISH INNOVATIVE EDUCATION CURRICULUM SYSTEM}

Innovative education curriculum system, like innovative education, is not a kind of physical existence, but as a concept, infiltrated in the education curriculum system [5]. Along with the innovative knowledge, innovative spirit, innovative personality and innovative ability etc., and in line with the principle of "solid basis, wide caliber, strong practice and stressed innovation", to create the professional curriculum system of electrical engineering and automation into a reasonable, complete, efficient and innovative organic integrity, to strengthen the professional basic education, broaden the caliber of professional basis, and completely eliminate the repetition of the content in teaching of different courses by means of step by step progressing from the professional basis and the main professional courses to the professional elective courses. In addition to retaining the professional classic curriculum such as power system analysis, power supply and distribution technology, power electronic technology, etc., add introductory course in the lower grade for early training of students' innovative consciousness, scientific research consciousness and interest; in order to enable students to master advanced design and debugging technology and to quickly adapt to the needs of the society on the talents, power system simulation and switching power supply technology and other courses with strong application and practicality have been set up; in order to improve students' innovative ability, practical ability, computer application ability, and the further study ability, single-chip programmable controller and other practical courses currently widely used in the field of automation have been set up.

\section{Optimize the TeACHING StAFF OF INNOVATIVE ENTREPRENEURIAL EDUCATION}

\section{A. Enhance Innovative Entrepreneurial Ability}

In order to enhance the vocational quality of the teachers in the innovative entrepreneurial center, regularly send professional teachers to the corresponding cooperative enterprises to participate in the project development and work practice, to explore the current popular new technologies, new ideas, and apply these to the training of innovative entrepreneurial colleague students, to enhance the practical ability of the teaching staff in innovative entrepreneurial education [6].

\section{B. Employ Staff from Enterprise}

Request the relevant enterprises to send outstanding core workers to serve as an internship instructor or part-time teacher in innovative entrepreneurial center, to guide students to practice, to provide students with relevant innovative entrepreneurial consultation. Strengthen the communication between the technical staff and the instructor, to gradually form a team of innovative entrepreneurial faculty with reasonable structure, high professional level and strong practical ability.

\section{Develop and Build up Teaching Staff}

Appropriately introduce professional counterpart talent, especially the experienced senior professionals. Encourage young teachers to focus on the improvement of their own qualities, to provide them with a relatively relaxed work and scientific research environment, so that young teachers could use winter or summer vacations or free time to explore and research with initiative, which will also tremendously influence the improvement of quality oriented education and practical ability education, as well as the overall quality of students of this school.

\section{Create InNOVATIVE ENTREPRENEURIAL AtMOSPHERE}

\section{A. Set up Multilevel Training Platform for Students}

For the purpose of "solid basis, practice stressed, strong innovation", integrate the practical teaching procedures in the electrical engineering and automation specialty training program, mainly from the basic practice, professional practice, comprehensive and innovative practice three levels to plan the open laboratory, experimental teaching demonstration center and practice base (Fig.1), and further build a student training platform to achieve practical education and innovative education.

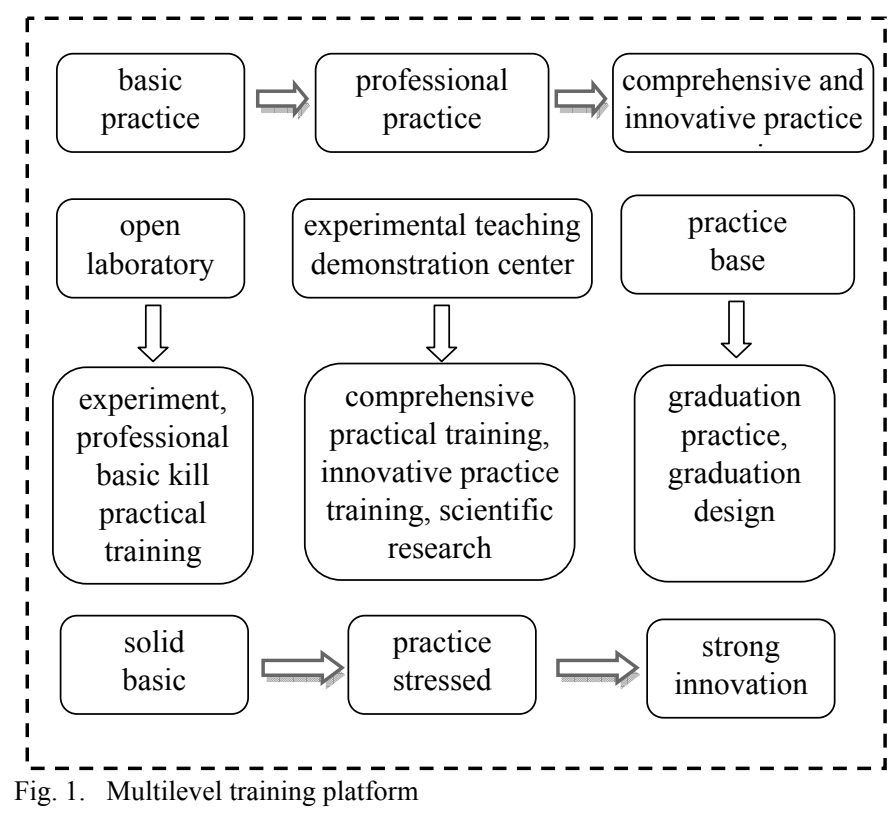

\section{B. Construct All-round Subject Competition System}

Construct the multilevel all-round subject competition system for electrical engineering and automation specialty (Fig.2). The subject competition shall be reasonably guided by the college, through the professional guidance and assistance 
of the teachers, to organize competition within the college. Based on the selection and training for competition within the college, gradually construct the all-round competition system composed of four stages (college level, school level, provincial level, national level competition), four levels (basic, professional, comprehensive, innovative competition), and four kinds of ability (basic, professional, comprehensive, innovative ability), step by step, level by level, with each other linked and gradually increase, from point to surface, to open up a platform for professional education.

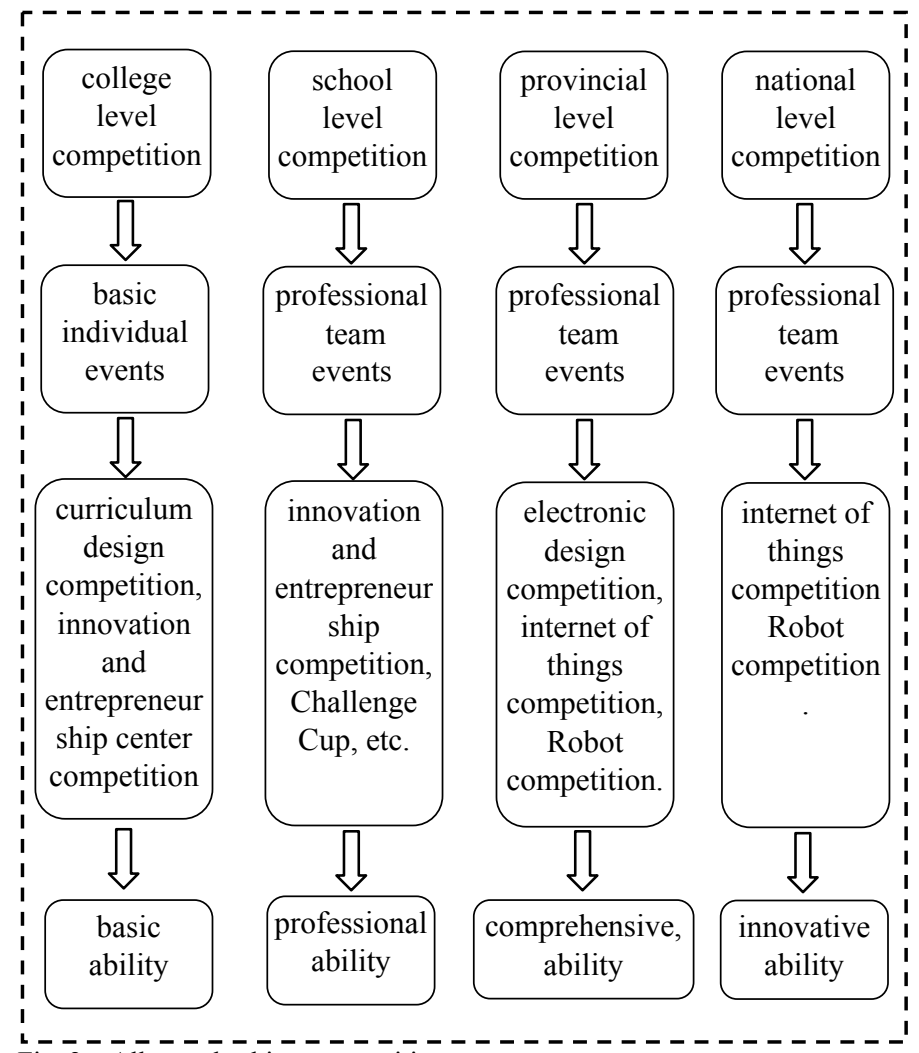

Fig. 2. All-round subject competition system

\section{Create Diversified Innovative Entrepreneurial Activities}

Through the organization of various competitions, lectures, forums, clubs, academic journals, simulation practice, etc., enrich the students' innovative entrepreneurial knowledge and experience, and enhance students' innovative spirit and entrepreneurial ability. Support the students to participate in academic meetings inside and outside the school, provide them with the opportunity to exchange experience, present achievements, and share resources of innovation and entrepreneurship. Make organic combination of innovative entrepreneurial education and the achievements of the practical activity, and actively create conditions for the outstanding entrepreneurial projects emerged from the innovative entrepreneurial activities, to effectively support a group of college students to achieve their own business. Regularly organize innovative entrepreneurial education experience exchange, seminars, research activities, to sum up and exchange the innovative entrepreneurial education experience, promote the outstanding achievements in innovative entrepreneurial education, organize the preparation of the advanced experience materials compilation in innovative entrepreneurial education and the college students' successful entrepreneurship casebook.

\section{Cultivate Science and Technology Entrepreneurial Team}

Through a variety of professional competition, innovative entrepreneurial projects, in accordance with the principle of "overall design and itemized implementation", implement under project responsibility system, applied "Project Management" method to organize the implementation, and to gradually cultivate the student-based technical science and technology entrepreneurial team, and cooperate with all kinds of entrepreneurship (incubation) base, college students pioneering park and entrepreneurial demonstration base, etc., so as to make the zero distance contact between students of the science and technology team and the actual entrepreneurship, regularly organize students to participate in college students' exhibition of science and technology works, encourage students to declare college students' innovative entrepreneurial training program, and guide students to declare the patents of science and technology achievements, to lay the foundation for future entrepreneurship and employment.

\section{E. Construct Practice Base in coalition with College and Enterprise}

In order to effectively improve the overall quality, the emphasis on the combination of theory and practice needs to be laid, to avoid the phenomenon of high theoretical level but low ability. Attention to the combination of school and enterprise can be paid, to build the practice innovative education base for students, making good use of the mutual relationship among industry, study and research, to closely integrate the school with the industry and the scientific research institutes to achieve the connection between school and industry, industry and specialty, taking advantages of the school and industry, scientific research and other units in innovative talents training, to establish extensive exchanges and contacts among teachers, students, schools and enterprises, to realize school classroom in the process of training [7].

\section{ADOPT DIVERSITY OF TEACHING METHODS}

\section{A. Project teaching method}

Scientific research and Practice method is adopted by the project teaching method based on the students' autonomy and exploratory learning. The engineering task converted by part of the scientific research shall be completed independently by the student team. The students shall be responsible from information collection, proposal design and implement, through which the students will study initiatively instead of passively, get interests in study and broaden their visions and train their team spirits. In order to make the students play a quick role after graduation, the simulating teaching method is adopted during the training, so that students can learn the necessary knowledge, skills and occupation ability.

\section{B. interactive teaching methods}

The interactive teaching method is adopted through heuristics, interactive discussion, participation and grouping, 
through which the students can find, raise and solve the problems, initiatively explore, discover, experience, discuss, summed up the study. Finally, the students' conversion from "What to learn" to "how to "learn" and higher thinking level shall be achieved during the realization of self-worth and stimulation of training interest. The role of teachers is mainly reflected in the guidance, supervision and examination.

\section{PERFECT DuAl StePPed Management AND GUARANTEE MECHANISM}

Establish and perfect dual stepped management and guarantee mechanism, namely, the stepped management of "Teacher - Electrical engineering -College of engineering and technology- Academic office" and "Student - Class teacher Student office - Student division", in which there is not only the top management from Academic office and Student division, but also the organization of Class teacher and the guidance of professional Teacher (Fig.3). The echelon interlocked and formed communication from top to bottom, feedback from each level and cooperative and collaborative management mechanism among the faculty, the school level and the school level departments, making the whole teaching more scientific and efficient, and providing guarantee for the cultivation of innovative entrepreneurial talents.

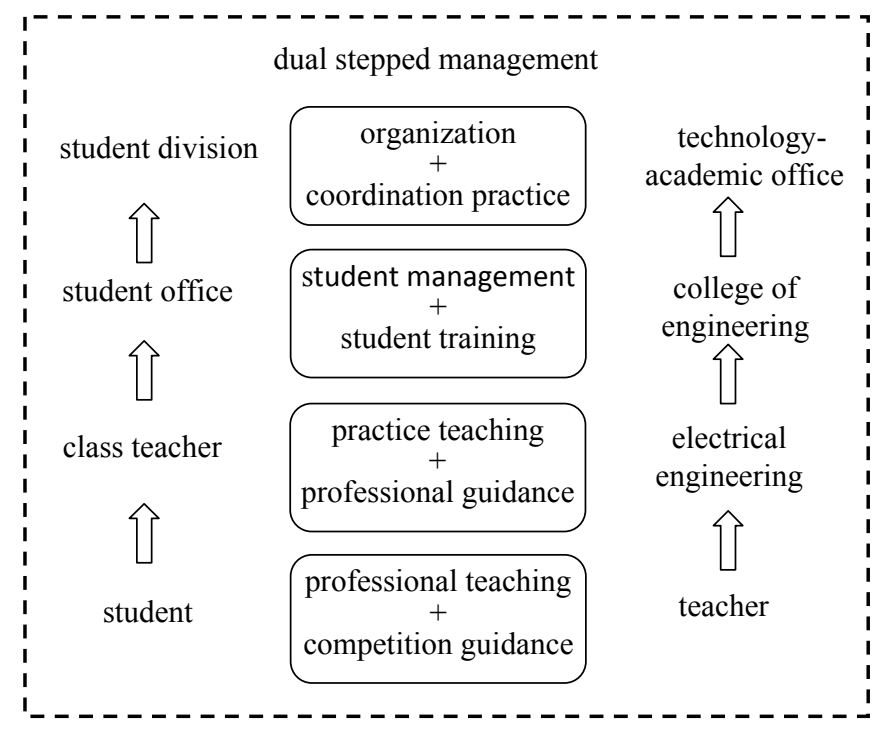

Fig. 3. Dual stepped subject competition management mechanism

\section{CONCLUSIONS}

In combination of the current practice of electrical specialty education, the concept of innovative talents training is built up with the aim of "focusing on cultivating job innovative entrepreneurs for all students". The innovative entrepreneurial teachers are optimized through regularly dispatching the professional teachers to participate in the enterprise project development and work practice, and inviting the excellent enterprise staff to be the part time teachers or instruction staff. The innovative entrepreneurial atmosphere is created through setting up multilevel training platform, constructing all-round subject competition system, creating diversified innovative entrepreneurial activities, cultivating science and technology entrepreneurial team, and constructing practice base in coalition with college. Integrate the innovative entrepreneurial education in colleges and universities into the talents training system, enrich the curriculum, strengthen the teachers, promote the close combination among teaching, scientific research and practice, break through the weak links of talents training, so that students' innovative spirit, entrepreneurial consciousness and innovative entrepreneurial ability are enhanced.

\section{ACKNOWLEDGMENT}

This work was financially supported by the Innovation and Entrepreneurship Training Reform Model Projects of Tianjin Agricultural University (20170812).

\section{REFERENCES}

[1] Jie Xiaolei, Yan Haimao, Zhu Weifeng, etc. Problems and countermeasures of innovation and entrepreneurship education in universities under the background of innovation driven [J]. Journal of ShangQiu normal university, 2017, 33(1), PP. 34-41

[2] Zhao Hui. Reflections on the innovation and entrepreneurship education of College Students [J]. Chinese University Science and technology, 2017(1), pp. 118-120.

[3] 2016 annual report on the frontiers and hot issues in China's Educational Research [J]. Education Research, 2017(2), PP. 12-25.

[4] Ma Suxia, Song Jiancheng, Lv Ping. Building the innovation system of the talents training for characteristic specialties [J], Journal of Higher Education Research, 2014, 37(3), PP. :67-69.

[5] Ma Tingqi, Shi Jiacui. Cultivation of innovative talents and reform of university personnel training mode $[\mathrm{J}]$. Modern Education Science, 2011(5), PP. 104-107

[6] Tang Genli, Wang Yanbo. Study on the cultivating path of college students' innovation and entrepreneurial ability [J]. Journal of SiChuan university of science \& engineering (social sciences edition), 2011, 26(3), PP. 76-79

[7] Zhou Ying, Wang ming, Yu houyong, etc. Discussions on talent subject - scientific research trinity undergraduate collaborative innovation training mode-Take school materials and textile, ZheJiang Sci-Tech university for exanple [J]. Journal of ZheJiang Sci-Tech University (Social Sciences), 2014, 32(1), PP. 83-88. 